University of Ecology and Management in Warsaw, Poland

k.adamiak@wseiz.pl

NAIR ViJESH VisWANATHAN

University of Ecology and Management in Warsaw, Poland

Vijesh.nair@wseiz.edu.pl

\title{
THE TRADITIONAL CONCEPT OF CLUSTER IN THE PROCESS OF CREATING ENERGY CLUSTERS IN MAZOVIAN DISTRICT
}

\begin{abstract}
The purpose of this article is to analyze the development of energy cluster in Poland, special in Mazovian district. A lot of clusters on the base of M.E. Porter definition exist in the literature and in the practice. Clusters are perceived as innovation-boosting initiative, which stimulates growth of the local economies and draw investors. An active Mazovian Energy Cluster of Poland is compared and the best possible outcome is measured in terms of cluster structure. Energy clusters are not typical co-operative relationships, so it is important to reflect on what clustering theory will be the best. This paper seeks to inform about the positive aspects of instilling an advanced structure compared to the traditional structure of energy cluster creation.
\end{abstract}

KEYWORDS: energy cluster, cooperation, coopetition, energy market, clusters.

\section{INTRODUCTION}

The subject of energy clusters is very often discussed. The reason is a change in the Renewable Energy Act, introduced in 2016 ${ }^{1}$. The aim of this article is to compare the classical theory of clusters with the principles of creating energy clusters. Energy clusters are different from the classical perception of a 
cluster because energy clusters do not have a product manufacturing process. It is important to consider how to create clusters of energy based on classical cluster theory

The article uses the method of direct interview. The Mazovia Energy Cluster, founded by the Mazovia Energy Agency, was used as an observation facility.

The term business cluster, also known as an industry cluster, competitive cluster, or Porterian cluster, was introduced and popularized by Michael Porter in The Competitive Advantage of Nations (1990). The importance of economic geography, or more correctly geographical economics, was also brought to attention by Paul Krugman in Geography and Trade (1991). Cluster development has since become a focus for many government programs. The underlying concept, which economists have referred to as agglomeration economies, dates back to 1890, and the work of Alfred Marshall.

Porter (1998), who is the most frequently cited advocate and analyst of cluster policy, defines clusters as Geographic concentrations of interconnected companies and institutions in a particular field, linked by commonalities and complementarities. However, Porter's definition is only one of many in the literature. The meaning of cluster is somewhat ambiguous, and the term is often used in different ways by different author. The same idea or concept was adapted by few other well-known authors like Rosenfeld (1997), Hill and Brennan (2000). Even before Porter presented a generalised idea, Krugman, (1991) in New economic geography stated clusters as co-location decisions of firms due to increasing returns to scale, lower costs of moving goods across space, etc. Robert Breault also stated that it's a combination of labour force with specialised skills and desired location. While Saxenian (1994) considered it as a bridge in building better social network and relationship among firma and industries. Glaeser and Gottlieb (2009), Enright (1998) considered clusters as agglomeration of financial, economical and business service firms. With the advancement of time more and more specified definition of cluster came into existence. In general, broader meaning of the term cluster and drawing upon the definitions of authors, we can state cluster to consist of firms in a region producing similar or related products, utilizing similar processes, or engaging in similar functions (headquarters; R\&D), the regional suppliers and customers 
of these firms, specialized labour skills (occupations) possessed by workers in the region employed by these firms, public and public-private programs that provide services to cluster members (e.g., customized training by community colleges), and institutions (e.g., universities, community colleges, industry and trade associations, public and private sector organizations) whose presence or interaction, to the extent it exists (i.e., the extent of interaction is an empirical question), results in cost-savings to firms and/or knowledge spillovers that produce cost savings and/or product or process innovations.

\section{Classification OF CLUSTERS}

The ultimate objective is to provide policy makers and practitioners with a means of intervening through strategies and policies that will produce higher regional economic growth. As indicated by the above discussion, clusters are a complex and elusive concept. One way of trying to come to grips with them is to attempt to classify different kinds of clusters according to their characteristics with the expectation that different kinds of clusters will be susceptible to different kinds of interventions (and that some kinds of clusters will be much more susceptible to interventions than will others).

One way of classifying clusters is according to the process through which cluster benefits are produced. Gordon and McCann posit three basic models of cluster processes: agglomeration economies, industrial complex, and social networks:

Cluster typology 1: Type of cluster by process;

- Pure agglomeration economies

- Industrial complex

- Social networks

Most clusters include: end-product or service companies; suppliers of specialized inputs, components, machinery, and services; financial institutions; and firms in related industries. Clusters also often include firms in downstream industries (channels or customers); producers of complementary products; and specialized infrastructure providers. Clusters also include a number of institutions, governmental or otherwise, that provide specialized training, education, information, research, and technical support 
(universities, think tanks, vocational training providers); and standards setting agencies. Government departments and regulatory agencies....can be considered part of it. Finally many clusters include trade associations and other collective sector bodies that support cluster members."

Cluster Typology 2: Type of cluster by category of membership. Cluster types can include relationships involving some combination of the following:

- A goods or service producing industry

- Suppliers or consumers of the industry

- Business or professional services related to these industries

- Trade associations consisting of firms in an industry or related industries (e.g., high technology)

- Workers with specialized skills or occupations utilized by these industries and workforce development institutions that provide training for workers in these skills (e.g., training programs, community colleges).

- Research institutions tied to products, processes, marketing, etc. related to the cluster (R\&D facilities, research universities)

- Government as regulator, facilitator, organizer, provider of incentives, investments, subsidies, etc.

Another set of cluster differences may have to do with the extent to which clusters are consciously organized at the regional level through creation of cluster organizations or whether they occur naturally.

Cluster typology 3: Cluster creation method

- Through natural processes

- Through human intervention to create, build upon, or improve a cluster

There are other typologies in the literature that are relevant to the research purposes of the authors. For example, Markusen (1996) creates a typology of a certain kind of cluster - industrial districts - based on the size of the firms that are part of it, their linkages and networks within and across the district, and the distribution of power among firms. Feldman and Audretsch (1999) classify 
clusters according to their ranking of the importance of different academic disciplines for the cluster and the level of innovation of the industries related to the cluster. Rosenfeld (1997) (as cited in Martin and Sunley, 2003) describes cluster typologies based on the evolution of the clustering process: working or overachieving clusters; latent or underachieving clusters; and potential clusters.

Enright (2003) characterizes clusters along various dimensions: geographic scope, density, breadth (range of horizontally related industries), depth (range of vertically related industries), activity base, geographic span of sales, strength of competitive position, stage of development, nature of the technological activities, innovative capacity, and ownership structure. He also uses several categories to characterize the state of development of clusters: working clusters, latent clusters, potential clusters, policy driven clusters (chosen by government to support, but that lack a critical mass of firms), and wishful thinking clusters (lacking a mass of firms and any source of advantage).

Thus, cluster theory and its application and cluster-based economic development policy, have been in the forefront of regional economic development theory and practice during the past decade. In particular, since analysis of and policies based on clusters have become a feature of much modern regional economic development policy, it is critical for practitioners to understand the dynamics of clusters and the limitations as well as advantages of employing cluster.

Thus, besides classification of cluster on the bases of typography, clusters can be divided into its various forms. Clusters can be divided into Innovation driven clusters, Industrial clusters, Management clusters, Textile clusters, Handloom clusters, etc. Of all clusters, Innovation-driven cluster have often taken the form of research-driven clusters, treating research and development activities as main source of innovations and competitiveness. Innovationdriven clusters include Energy clusters, Biotechnology clusters, Information Technology clusters, Nanotechnology clusters etc.

\section{ENERGY CLUSTER}

The perspective of a constant economic growth impacts on the increasing demand of energy. The threat of climate change caused by over-dependence on fossil fuels, and growing public concern on the risks of environment 
pollution, is ensuring that demand for clean technologies and energy from RES is getting even stronger. Economists stated that, technological advancement alone will not reduce the risks but proper management of present energy will also play an important role towards the same. So, under proper scrutiny and amalgamation of business, government and science, energy clusters were created. Energy clusters are one of the innovation driven clusters, an emerging sector, which stimulates growth of local economies and draw investors. Mazovia Energy Cluster, Ekoenergia, Świetokrzysko-Podkarpacki Energy Cluster, Lublin Eco-Energy Cluster, Baltic Eco-Energy Cluster etc. are few energy related clusters of Poland.

Considering the main aim of this paper i.e. instil traditional concept of cluster in the process of creating energy clusters in Mazovian district, a detailed study was done on one of the most successful cluster in Mazovia i.e. Mazovia Energy cluster co-ordinated under Mazovia Energy Agency (Mazowiecka Agencja Energetyczna)

\section{Mazowiecka Agencja Energetyczna (MAE)}

On the initiative of the Council. Entrepreneurship at the Marshal of the Mazowieckie Province on 14 August 2007, the 69 meeting of the Regional Board Mazowiecki was decided to start the establishment of the Mazovian Energy Agency, whose creation and operation would be funded under the EU's Intelligent Energy Europe (IEE). The principles of cooperation set forth in the resolution of the Regional Board Mazowiecki No. 1828/76/07 dated 11.09.2007 r.

Resolution No. 2388/278/09 Regional Board Mazowiecki of 15 September 2009. it led to the entry into force of Annex changing No. 1 to the grant entry IEA as a coordinator of the project, and thus completed the commissioning of the project entitled. "Mazovian Energy Agency" by the Regional Government Mazowiecki. Annex amending the No. 1 to the Agreement Grant came into force on 1 October 2009. in this day Mazovian Energy Agency began implementation of the action provided for in the Grant Agreement.

Today, one of the biggest organisations consisting of nearby 183 members spread over whole Mazovia district, with many ongoing projects in hand. Under this organisation, an energy cluster was introduced named Mazovia 
Energy Cluster, with specified goals and objectives. Mazovia Energy Agency has established the Mazovia Energy Cluster to improve energy efficiency in the Region, creating a platform of cooperation for public institutions, local governments, business and R\&D.

To get better knowledge about organisational structure and work strategies, an interview was conducted with Mr. Dubiński Bartosz, CEO, Mazovia Energy Cluster. A shot summary of the interview is written below:

The major problem prevailing in market, currently according to Mazovia Energy Agency is not creation of energy; in fact we have enough energy in market. The only concern is management of this energy to consumer end. Currently the cluster is working with cooperation and co-ordination of various entities involved in it. This cluster is different in its economy, its combination of individual subjects, companies, universities which work together on special projects for innovations, for new productions and product. It's a combination of 30-40 firms, universities, and companies, decided to sign the letter of intent without any special legal circumstances, just together work on different topics on different projects. The most comprehensive energy efficiency and RES offer on the market is possible when integrating variety of competences and energy sector stakeholders (i.e. members). The members or entities in this cluster include various local municipal units, marketing agencies, research and development centres, academic centres, small-and-medium size enterprises (manufactures and service providers in the field of energy efficiency and RES), consultancy agencies, financial institutions, training institutions, certifying bodies, energy sector institutions and governmental and non-governmental organizations. It is the cooperation between these entities and management which drives this cluster into success.

All the entities in this cluster work towards certain achieving certain objectives which include strengthening competitiveness of the region, increasing competitiveness of enterprises, improving information flow between science and business, promotion of energy-wise behaviour, reduction of harmful impact on the environment, providing services to increase energy efficiency, strengthening co-operation between local/regional government, universities and research centres and business sector, popularization of proecological behaviour, promotion of Mazovia Region as a place of effective 
investment, improving energy safety of Mazovia Region, promoting RES investments and Increasing the number of students at technical studies (with energy faculties).

For achieving objectives, certain important activities are done by the cluster. They prepare and organize market by promoting energy efficiency and RES, promoting energy efficiency know how to the end-users and organizing trainings, conferences and seminars. Implementation of financial support for activities taken in the field of energy efficiency and RES, by elaborating standards for energy monitoring systems (smart metering) and even monitoring of energy use in public institutions. Various information and consultation centres are setup advising on energy efficiency and RES.

Discussion continued on various projects under the energy cluster, few are the ongoing projects and many waiting for the approval from the cluster management. According to the amendment of the Act on Renewable Energy Sources(RES), which entered into force on $1^{\text {st }}$ July 2016, in the first version of the draft amendment, the concept of macrocluster and energy microcluster was introduced, which ultimately was abandoned to the general concept of energy cluster. As defined in Art. 2 pt 15aof the Act on Renewable Energy, some constitutive characteristics of the energy cluster can be pointed out, as civil-law stakeholder agreements aiming at realization of a specific economic project in the field of electricity. The civil law agreement - in accordance with the lingual meaning of the term - can be both a contract not called, as well as a contract of a civil partnership or even a commercial company. The purpose of energy cluster agreement must be to generate and balance the demand, distribution or trading of RES energy within rated voltage of less than $110 \mathrm{kV}$. The cluster activity area must not exceed the boundaries of one county or 5 municipalities. According to these amendments, a new project in the region of Legionowo is implemented. Compared to earlier project, this new project is a business project with a list of specific investors and calculated profit generation at the end of the project.

Mazovia Energy Cluster is a non-profitable business venture, which works on the cooperation between the entities in this cluster. A flexible organisational structure is followed in the cluster, along with no specific 
financial investment. A major investment in this organisation is their investment in building public relations. Today the major share of their success is the result of better relationship maintained by the management among their members. The business entities of the cluster gained access to higher market, the institutions or universities got better understanding of the present scenario in the market. Continuous flow of information is possible among the members. Each and every member has access to any area of their interest with in the cluster reach. Every entity grows within the cluster as they work on a very simple principle of competition in cooperation. This make it even better because it's good for the cluster as all the companies compete in very positive sense and are more likely to produce better results than just tailoring the market.

Coming to conclusion of the interview, various drawbacks like lack of motivation amongst the members, no specific strategy and flexible organisational structure were discussed. Every positive aspect comes with certain ill effects, which encountered with considerable counter measurements can reduce the impact. The major problem arising in this cluster is its mere existence. Since it is following a flexible structure, the chance of members leaving the cluster is more, which will indirectly reduce the importance of cluster in market and eventually shutting down. In its developing phase, newer strategies and objectives must be executed. New promotional events, marketing approach, profitable business endeavours should be enacted. Evolving the cluster from local region to national and international level by linking to new clusters in same field or expanding the horizon by affiliating with cluster from different backgrounds.

Considering the present day energy scenario, Is there any need for creating an energy cluster? Why is the energy clusters created? If created, what is the best organisational structure for any energy cluster? Who all should be the members of the cluster?

\section{WHY ARE THE ENERGY CLUSTERS CREATED?}

Generally energy cluster is a project jointly implemented by entities interested in developing, implementation and commercialization of innovative technologies in the area of energy production, management or 
distribution. The cluster consists of numerous entities specialising in science and business (private/public companies), industries, consulting companies, educational institution, research and development units.

The main role of energy cluster will be based on joint research, development and implementation work, which aim to develop innovative methods in developing a better energy market. Energy clusters can work as a base to establish international cooperation and to exchange information, technologies, scientists, business professionals, which as an individual entity can't be done. It will cooperate with major power industries and work in coordination with them, keeping in mind the goals for energy development, better research and development, management and distribution of energy. Major aim can be that it works towards achieving goal to reduce the loss of power consumption in the Mazovia region along with improving the use of renewable energy in energy production. If the power consumption rate of an area is reduced even a slightest percent, there is large scope of saving energy which can be utilised in other forms. Technological advancement in reducing the CO2 level in the atmosphere by installation of new equipment in companies, industries, vehicles etc. Upgrade the distribution channel across and lay-out better strategic plan for energy management.

\section{ENERGY CLUSTER MANAGEMENT IN MAZOVIA}

As discussed earlier, energy cluster usually consists of industries producing energies, management or consulting firms working on management, government regulating rules and regulations and institutions playing just as a spectator. But looking up to present energy market of Poland, today, major source of energy generated from conventional source are used for electricity generation and major electricity generating companies are PGE (Polska Grupa Energetyczna), ENERGA, ENEA, TAURON, RWE POLSKA. Generation, distribution and management are handled under their banner. In 2015 statistics shows that PGE holds 29,7\%, ENERGA has 12,8\%, ENEA 12,2\%, Tauron $27,3 \%$ and remaining by different agencies ${ }^{2}$. Coming to Mazovia, while examining the electricity distribution of Mazovia voivodeship, it is clear that PGE holds major electricity grids. 
Figure 1.

Distribution network of Mazovia Source: http://www.paih.gov.pl

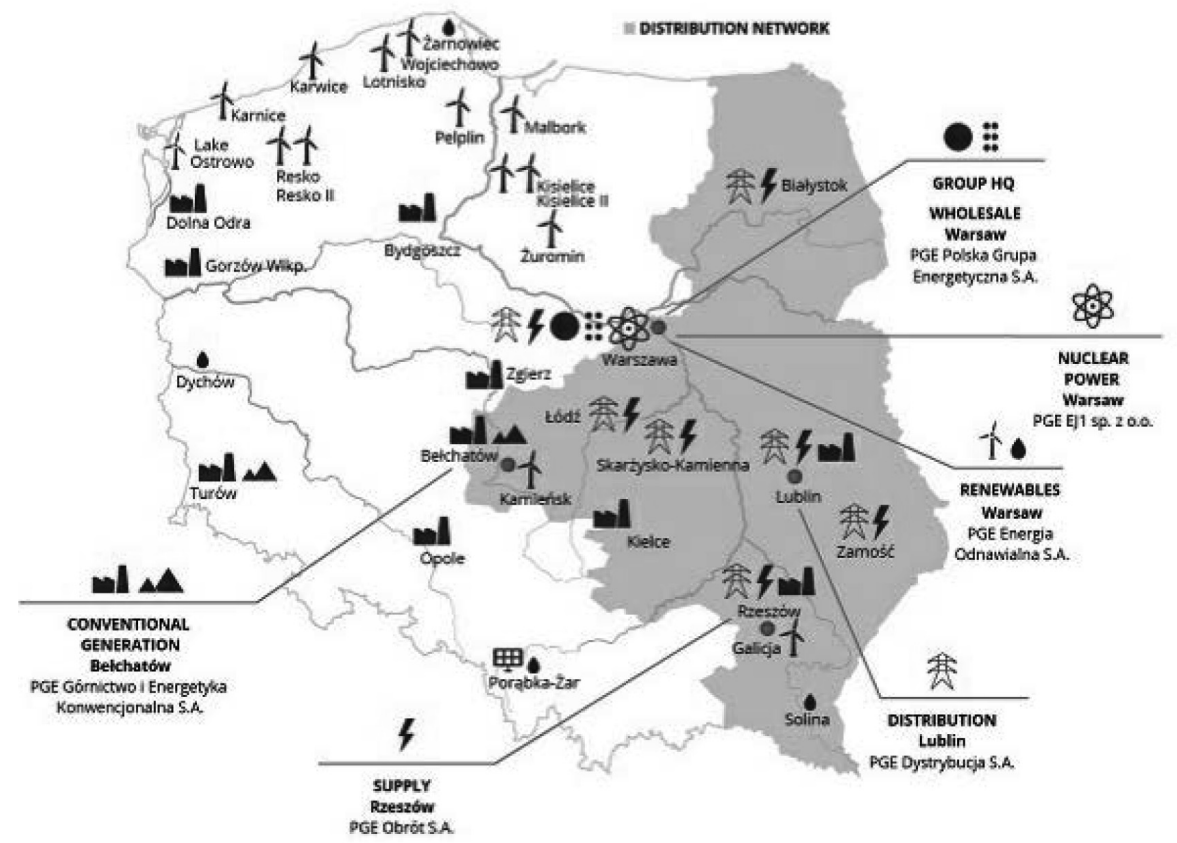

When such a power industry is already in locality, to create new production unit is not possible, so creating an energy cluster with production is not possible in Mazovia. Hence, an energy cluster has to be created with coordination and cooperation of this power industry. Now the question is what will be the best energy cluster for Mazovia district? What will be best management structure for energy cluster? Detailed information of best possible energy cluster according to authors' opinion is presented in coming sub-chapters.

\section{(i) Energy cluster structure}

Various energy clusters are created on the bases of the requirement of that geographical area. The agglomeration industries, educational institutes or business firms are usually the main entities included in the cluster. In energy clusters, the industries have the major share as they are the core for any 
production in the area. But when a scenario is generated where you already have a prominent industry, which controls most of the production sector in electricity then creating an energy cluster with them as a center won't be an appropriate approach. When such a situation arises, creation of energy cluster on traditional definition is not suitable. Going through various energy cluster article, authors suggests one of the way of creating an energy cluster in Mazovia district.

Before creating an energy cluster, the entities which will be the members of the cluster must be decided. A simple structure for energy cluster is shown below along with its entities:

Figure 2.

\section{Energy cluster Source: Self}

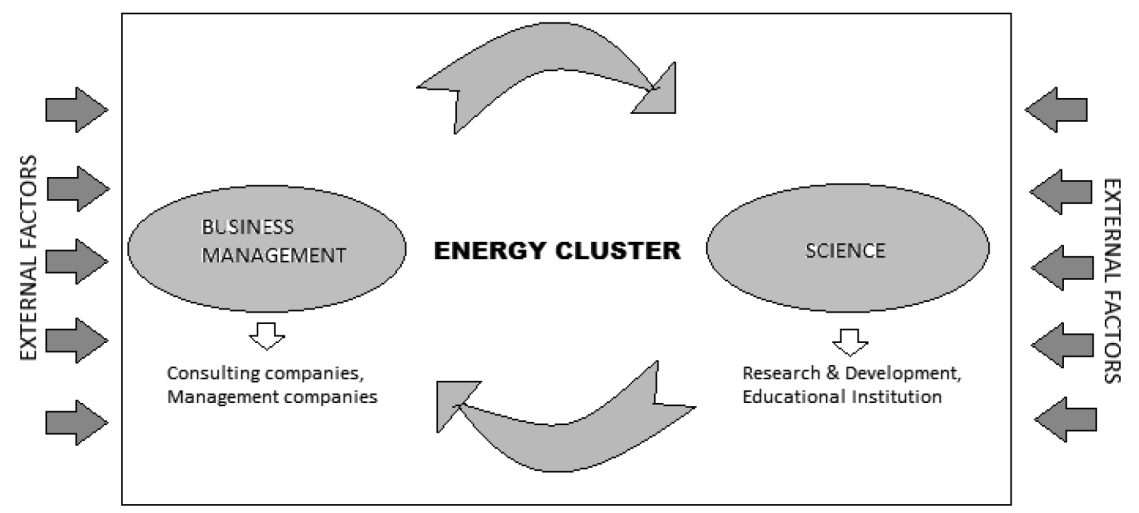

In this structure of energy cluster, science and business are the only two entities which will sign an official civil agreement of partnership. The first step is the leadership group formation. Active clustering needs commitment from preferred leaders. Ideal is to find a group with a balance of skills and what is able to work as a team. Here the coordinator has a key role when establishing the group. The leadership group's members are the clusters movers and shakers. The coordinator invites for the group, usually invitees are the members of a cluster. Group is formed from private and public sector representatives and institutes, but should not be dominated by the public figures. There are usually less than 10 members in a group. Leadership group 
should follow the private sector culture even there might be financers among the public members. The coordinator should select the group knowing and understanding the potential members life cycles - how deeply still in actual business, how much there are leisure time, what other roles the potential member has already committed.

Coordinator role is the key role and quite often even the personal relationships define the interest. In Coordinator's role the personality and knowledge really matters. Cluster coordinator's role is challenging and not easy. Coordinator's role is to act as a change agent and catalyst. Coordinator is also a networker and relationships builder. Coordinator's role should be on a long-term basis, the person is neutral broker, who has responsibility for instigating cluster development programs, and ensuring that the initiatives continue to be upgraded. Coordinator has to be also credible and have excellent integrity. As said, role is challenging, but also to find excellent coordinator, can be very challenging.

The coordinator can be a representative from the business sector or any individual from the institute or a special recruitment process is applied for selecting one from the crowd. Certain qualities of a coordinator includes being passionate, a network builder, an active person, an eminent personality and of course a smart worker.

Cooperation is the working principle of this cluster. Below diagram shows the functioning of this cluster:

Figure 3.

Working of cluster Source: Self

\section{ENERGY CLUSTER}

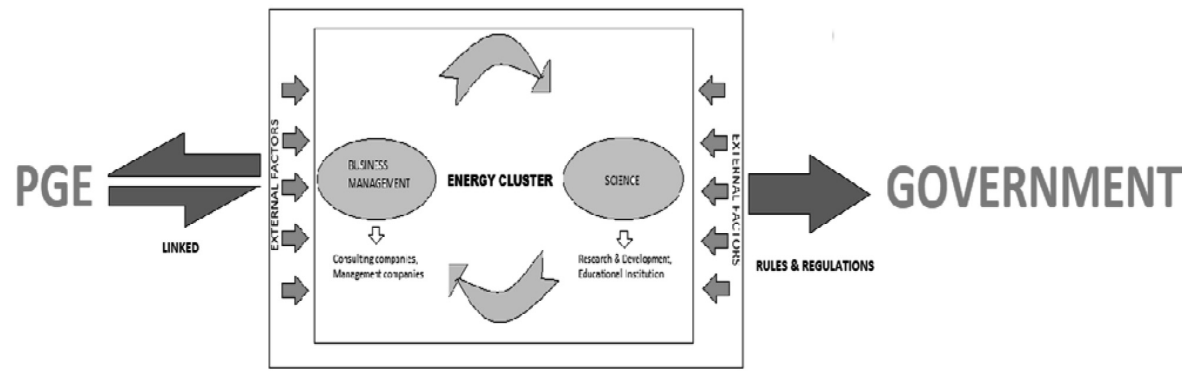


The working of the energy cluster can be divided into 3 parts:

\section{(I) Energy cluster}

The entities in the cluster coordinate and cooperate with one another to accumulate the information and requirement of the cluster. Working towards the cluster objective, they form a bond between them and each entity gets the benefit of the cluster. The major work within the cluster will be creating new technological advancement and business strategies for the customers and individuals of the clusters.

\section{(II) Energy cluster \& PGE}

PGE will be linked with the energy cluster but will not have any partnership with in the cluster. It won't be an entity in the cluster. The major benefit of PGE being the a linked associate is that, it will have access to the industrial sector in Mazovia district and in return PGE will gain the advantage of research and development in the field of electricity. PGE will invest in the cluster just as an investor and can get benefit of both financial and technological advancements. The members of cluster will be able to have better understanding of the whole market as they have direct access to the electrical industry. The researchers will be backed up with financial sources needed for their research.

\section{(III) Energy cluster \& government}

Government keeps the check on the rules and regulations in the working of energy cluster. They are neither partners nor associate with the cluster. The main function of government with energy cluster is to regulate new and better rules for the business entities and cluster so that maximum benefit can be achieved. For example government can reduce the price for solar grids, formulate new laws for generating energy from renewable energy sources, which indirectly improve the living standards of local community.

Thus, an energy cluster created on this base would generate maximum benefits ${ }^{3}$ to both the local population and entities involved in the cluster. The efficiency ${ }^{4}$ of the cluster increases with better cluster governance. Even if this may be the most suitable cluster structure but there are few advantages and disadvantages in this model. (Note: Advantages and disadvantages of this model are mentioned excluding the usual benefits and risks of cluster) 


\section{Advantages:}

1. Members can operate with higher efficiency drawing on more specialised assets with shorter reaction time then they could do in isolation.

2. Research institution can achieve higher levels of innovation, knowledge spillovers and the close interaction with the customer and other companies create more new ideas and provide intense pressure to innovate while the cluster environment lowers the cost of experimenting.

3. Cluster will facilitate commercialization and new business formation. It's efficient access to specialized inputs, services, employees, information, institutions, training programs and other public goods.

4. With development of cluster there will be an increase in employment, the growth of wages and profits, intensification of entrepreneurial activity, etc. along-with improving the welfare of the entire population.

Thus, the presence of cluster structures in the regional economy can successfully combine the interests of business, government, science and education and coordinate efforts and financial resources to create new products and technologies, and output them to the market.

\section{Disadvantages:}

1. In a context of rapidly changing technology, cluster firms become more vulnerable if they are locked in old technologies and if they don't develop enough flexibility to adopt themselves to the changes.

2. At regional level, the force of attraction of a region should not be overestimated, as only few clusters are internationally recognised. Disadvantages can be more visible in recession period.

Thus, the list of advantages and disadvantages mentioned above is sustained by only theoretical and empirical studies.

\section{SUMMARIZING}

Literary analysis, indicating that the traditional approach to clustering is not used in the theory of creating energy clusters in Poland. Elements of an energy cluster will be similar to classical clustering theory, only the links 
between them will have features characteristic of the service. There is no common product and this type of cluster is not typical. The most important element in the cluster is the cluster coordinator, which shapes relations between individual participants and determines the scope of coopetition. Experience has shown that the creation of energy clusters is conducive to the development of local entrepreneurship and individual cluster members. Growing demand for energy should be a warning sign and a step to change the current energy policy in Poland.

\section{References:}

Wolman H. and Hincapie D. (2010), Clusters and Cluster-Based Development: A Literature Review and Policy Discussion p 2- 10, Washington, DC. https://doi. org/10.1177/0891242413517136

Chatterji A., Glaeser E. and Kerr W. (2013), Clusters of Entrepreneurship and Innovation, Harvard University, Massachusetts

Miroslaw L. and Curie M. (2015), Biotechnology clusters in Poland, Joint International Conference, Italy. ISSN 2232-3309.

Adrian T.H. Kuah (2002), Cluster Theory and Practices: Advantages for the Small Business Locating in a Vibrant Cluster, Huddersfield, UK

Benchmarking klastrów w Polsce - edycja 2014, PARP Warszawa

Boschma R. and Fornahl D.(2011), Cluster Evolution and a Roadmap for Future Research Utrecht, Netherland

\section{Endnotes}

${ }^{1} \mathrm{http}: / /$ wysokienapiecie.pl/prawo-energetyczne/1638-klaster-energii-nowosc-wustawie-o-oze

${ }^{2}$ https://www.are.waw.pl/index.php?dzid=335\&did=2006

${ }^{3}$ benefits can be monetary, better public relation, better living standards

${ }^{4}$ efficiency is measured on the base of cooperation and coordination 